\title{
Metal-Organic-Framework-Derived Mesoporous Carbon Nanospheres Containing Porphyrin-Like Metal Centers for Conformal Phototherapy
}

\author{
Shunhao Wang, Lu Shang, Linlin Li, Yingjie Yu, Chongwei Chi, Kun Wang, Jie Zhang, \\ Run Shi, Heyun Shen, Geoffrey I. N. Waterhouse, Sijin Liu, * Jie Tian, Tierui Zhang,* \\ and Huipu Liu*
}

Phototherapy encompasses two therapeutic techniques: photothermal therapy (PTT) and photodynamic therapy (PDT). PTT involves photothermal agents, which rapidly convert nearinfrared (NIR) light energy into ablative heat to kill cancer cells via electron-phonon and phonon-phonon coupling interactions. ${ }^{[1]}$ In PDT, photosensitizers activate reactive oxygen species (ROS) under specific wavelength irradiation, which can irreversibly destroy nearby cancer cells following a sequence of biochemical and biophysical process. ${ }^{[2]}$

Porphyrin and their derivatives are commonly used photosensitizers in PDT, and approved by the U.S. Food and Drug administration (FDA). ${ }^{[3]}$ However, porphyrin-based sensitizers have a number of drawbacks which hinder their clinical application, such as their instability to photo-bleaching, hydrophobic nature, poor penetration depth, and phototoxicity. Considerable research effort has been directed toward improving photosensitizer delivery through the use of nanocarriers including polymeric micelles, ${ }^{[4]}$ liposomal, ${ }^{[5]}$ dendrimers, ${ }^{[6]}$ silica-based, ${ }^{[7]}$ upconversion nanoparticles, ${ }^{[8]}$ and so forth. However, premature leakage, instability, and low activity of photosensitizer-carrier systems remain obstacles to high treatment efficiencies and improved patient outcomes. Strong incentives exist to develop novel porphyrin-based photosensitizers with good stability, low toxicity, water solubility, and deeper penetration depth.

Besides PDT applications, porphyrins and their derivatives also exhibit oxygen reduction reaction (ORR) activity. ${ }^{[9]}$ However, their ORR activity decreases rapidly with use due to their poor stability under reaction conditions. Recently, transition metal and nitrogen co-doped carbons $(\mathrm{M}-\mathrm{N}-\mathrm{C}$, where $\mathrm{M}=\mathrm{Fe}$, $\mathrm{Co}, \mathrm{Zn}$, etc.) possessing metal coordination centers comparable to those present in porphyrin macrocycles were reported as efficient and stable electrocatalysts for ORR. ${ }^{[10]} \mathrm{M}-\mathrm{N}-\mathrm{C}$ can be obtained via the calcination of precursors containing transition metals, nitrogen, and carbon under high temperature. ${ }^{[1]}$ Like porphyrins, $\mathrm{M}-\mathrm{N}-\mathrm{C}$ can coordinate metals in different ways, changing their redox state, axial ligation, and electronic structure, thereby creating active sites for reducing $\mathrm{O}_{2}$ to $\mathrm{H}_{2} \mathrm{O}$ or $\mathrm{OH}^{-}{ }^{-[12]}$ In view of the fact that both ORR and PDT involve
S. H. Wang, Dr. H. Y. Shen, Prof. H. Y. Liu

Beijing Key Laboratory of Bioprocess

Beijing Advanced Innovation Center for Soft Matter

Science and Engineering

Beijing Laboratory of Biomedical Materials

Beijing University of Chemical Technology

Beijing 100029, P. R. China

E-mail: liuhy@mail.buct.edu.cn

S. H. Wang, Dr. L. Shang, R. Shi, Prof. T. Zhang

Key Laboratory of Photochemical Conversion

and Optoelectronic Materials

Technical Institute of Physics and Chemistry

Chinese Academy of Sciences

Beijing 100190, P. R. China

E-mail: tierui@mail.ipc.ac.cn

S. H. Wang, J. Zhang, Prof. S. J. Liu

State Key Laboratory of Environmental Chemistry and Ecotoxicology

Research Center for Eco-Environmental Sciences

Chinese Academy of Sciences

Beijing 100085, P. R. China

E-mail: sjliu@rcees.ac.cn

S. H. Wang, J. Zhang, R. Shi

University of Chinese Academy of Sciences

Beijing 100049, P. R. China
Dr. L. L. Li

Beijing Institute of Nanoenergy and Nanosystems National Center for Nanoscience

and Technology (NCNST)

Chinese Academy of Sciences

Beijing 100083, P. R. China

Dr. Y. J. Yu

Department of Materials Science and Engineering

State University of New York at Stony Brook

Stony Brook, NY 11790, USA

Dr. C. W. Chi, Dr. K. Wang, Prof. J. Tian

Key Laboratory of Molecular Imaging

The State Key Laboratory of Management

and Control for Complex Systems

Institute of Automation

Chinese Academy of Sciences

Beijing 100190, P. R. China

Dr. G. I. N. Waterhouse

School of Chemical Sciences

The University of Auckland

Auckland 1142, New Zealand

DOI: 10.1002/adma.201602197 
oxygen activation, it is highly plausible that $\mathrm{M}-\mathrm{N}-\mathrm{C}$ catalysts with porphyrin-like metal centers could serve as stable photosensitizer candidates for PDT cancer therapy. Surprisingly, no literature studies evaluating the performance of $\mathrm{M}-\mathrm{N}-\mathrm{C}$ for PDT have been reported to date, motivating a detailed investigation.

Herein, we successfully synthesized monodisperse mesoporous carbon nanospheres containing porphyrin-like zinc centers (denoted as "PMCS") that were modified by PEG-vitamin E (PEG-VE) (PEGylated PMCS) and confirmed that such materials could be used as stable photosensitizers in phototherapy. The PMCS were obtained from an imidazolate framework (ZIF-8) precursor by a surface protected pyrolysis strategy.[13] The strategy involved surface coating of ZIF-8 with mesoporous silica $\left(\mathrm{mSiO}_{2}\right),{ }^{[14]}$ followed by high-temperature pyrolysis and finally removal of the $\mathrm{mSiO}_{2}$ shell by $\mathrm{NaOH}$ etching. This surface protection step prevented the irreversible aggregation of $\mathrm{M}-\mathrm{N}-\mathrm{C}$ that typically occurs during high-temperature pyrolysis of ZIF-8, thereby affording PMCS with fast in vivo nanoparticle transport and enhanced permeability and retention (EPR) effects. ${ }^{[15]}$ X-ray absorption fine structure (XAFS) spectroscopy here for the first time probed the coordination structure of zinc atoms and revealed zinc-centered porphyrin-like structure in the PMCS. Interestingly, the singlet oxygen $\left({ }^{1} \mathrm{O}_{2}\right)$ quantum yield of PMCS was comparable with indocyanine green (ICG), an FDA approved NIR fluorescent dye/photosensitizer. Furthermore, the black PMCS nanoparticles show exceptionally high photothermal conversion efficiency (33.0\%) compared with other mesoporous carbon sphere samples $(22.2 \%)^{[16]}$ or widely used PTT agents, such as gold nanoshells $(13.0 \%),{ }^{[17]}$ gold nanorods $(21.0 \%),{ }^{[17]}$ and copper sulfide $(16.3 \%) .{ }^{[18]}$ Most importantly, NIR thermal and photoacoustic (PA) contrast properties of the PMCS allow real-time imaging-guided precise therapy. We believe that this study lays a firm foundation for the wider use of carbon nanoparticles containing porphyrin-like moieties in conformal phototherapy.

PMCS were synthesized via carbonization of a ZIF-8 metal-organic framework, (MOF) using a mesoporous-silica protection strategy (Figure 1a, and Figure S1a-d, Supporting Information). In this strategy, $\mathrm{mSiO}_{2}$ shell was first coated on the surface of ZIF-8 to provide a physical barrier against aggregation during the subsequent high-temperature pyrolysis stage. The resulting ZIF-8@ $\mathrm{mSiO}_{2}$ was then transferred to $\mathrm{PMCS} @ \mathrm{mSiO}_{2}$ by high-temperature treatment. Finally, by

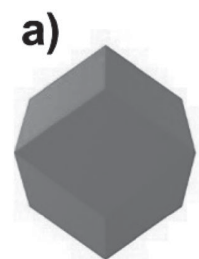

ZIF-8 trum of PMCS. etching the $\mathrm{mSiO}_{2}$ shell with aqueous $\mathrm{NaOH}$, monodisperse PMCS nanoparticles with an average diameter of $\approx 140 \mathrm{~nm}$ were obtained (Figure 1b, and Figure S1e, Supporting Information). The size and monodispersity of PMCS are suitable for rapid nanoparticle uptake and penetration for cancer therapy due to the EPR effect. ${ }^{[19]}$ Nitrogen adsorption-desorption isotherms for PMCS revealed a microporous-mesoporous material with a specific surface area of $950 \mathrm{~m}^{2} \mathrm{~g}^{-1}$, a cumulative pore volume
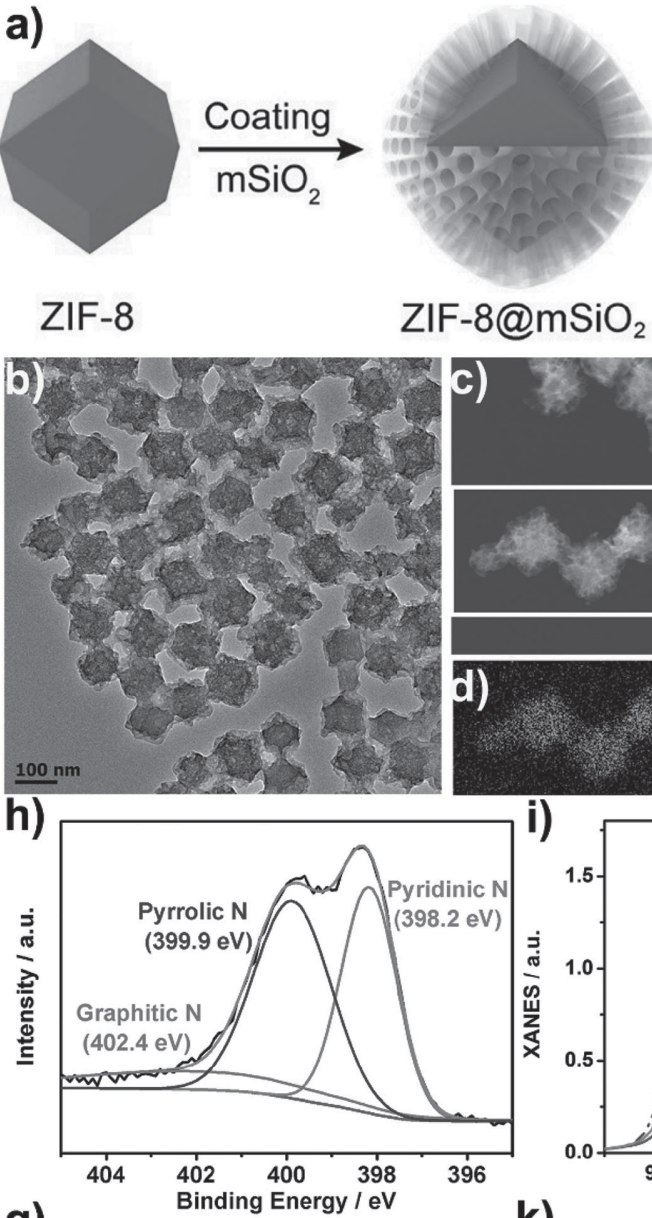

$\mathrm{ZIF-8@mSiO} 2$
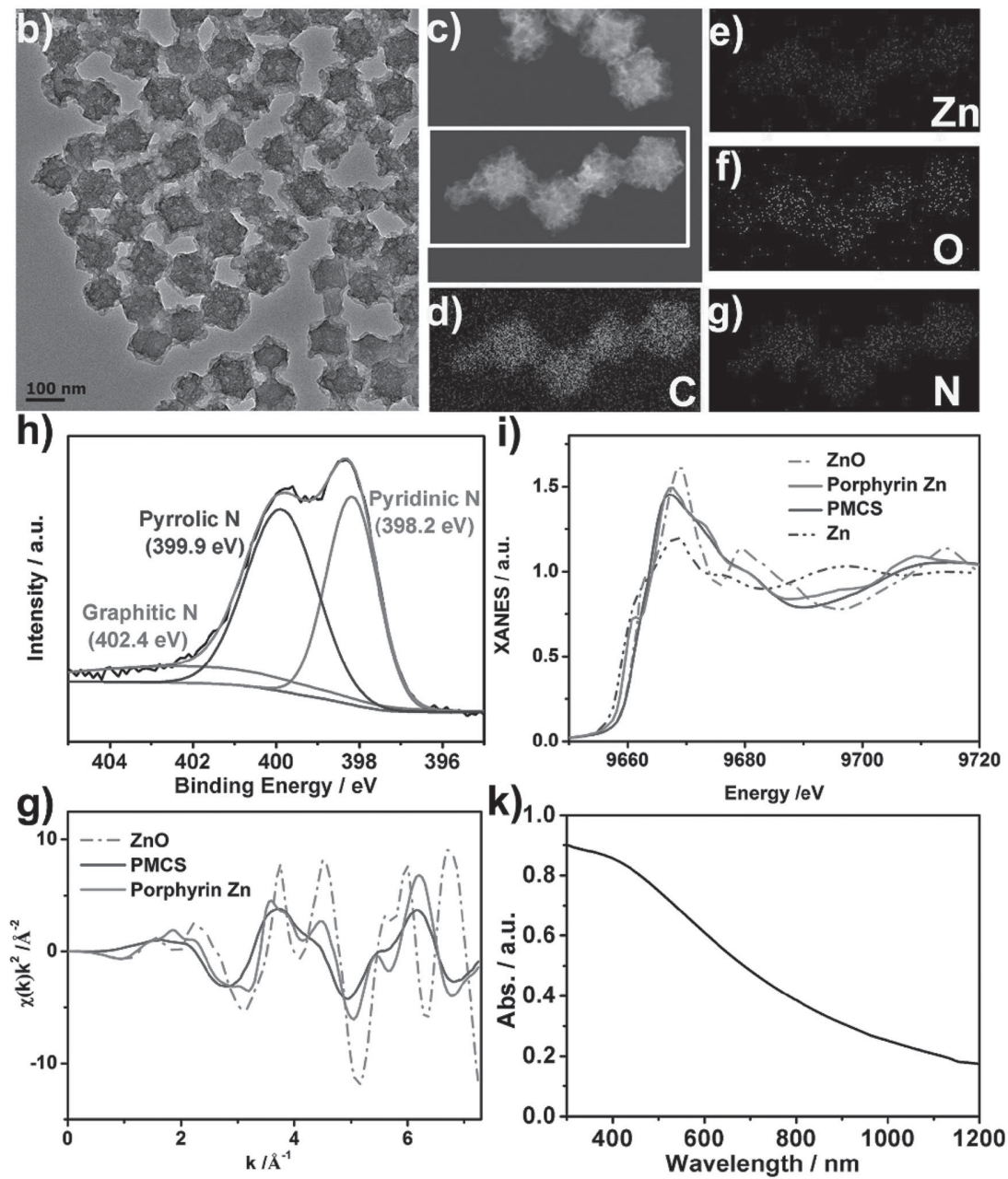

Figure 1. Synthesis and characterization data for mesoporous carbon nanospheres containing porphyrin-like metal centers (PMCS). a) Scheme for PMCS synthesis; b) TEM and c) STEM images, scale bar is $100 \mathrm{~nm}$. Element mapping for d) carbon, e) zinc, f) oxygen, and g) nitrogen, h) high-resolution N1s XPS spectrum for PMCS, i) Zn K-edge XANES spectra for PMCS and $\mathrm{Zn}$-containing reference materials including $\mathrm{ZnO}$, a porphyrin $\mathrm{Zn}$, and a metallic $\mathrm{Zn}$ foil, j) $\mathrm{Zn}$ K-edge EXAFS data for ZnO, PMCS, and a porphyrin Zn, and k) UV-vis-NIR absorption spec- 
of $1.97 \mathrm{~cm}^{3} \mathrm{~g}^{-1}$, and pore sizes of 1.3 and $3.9 \mathrm{~nm}$ (Figure $\mathrm{S} 2$, Supporting Information). The PMCS retained much of the internal porosity of the ZIF-8 precursor, aided obviously by the mesoporous silica protection strategy adopted herein. The form of carbon material in PCMS was confirmed by powder X-ray diffraction (XRD) (Figure S3, Supporting Information) and the Raman spectroscopy (Figure S4, Supporting Information). In the XRD pattern, a broad peak at $\approx 26^{\circ}$ is indexed as the (002) plane of the graphitic carbon, with no signals of $\mathrm{ZnO}$ or Zn metal element. ${ }^{[20]}$ In the Raman spectrum, two peaks at 1358 and $1580 \mathrm{~cm}^{-1}$ are observed, and readily assigned to defect-induced breathing mode of $\mathrm{sp}^{2}$ rings (D-band) and the stretching vibrations of $\mathrm{sp}^{2}$-bonded (G-band) carbon, respectively. ${ }^{[21]}$ The $I_{\mathrm{D}} / I_{\mathrm{G}}$ ratio of $\approx 0.9$ was quite high for a heteroatom doped carbon material, as heteroatoms generally create defects in the $\mathrm{sp}^{2}$ carbon lattice. ${ }^{[22]}$ The heteroatom doping was confirmed by element mapping and X-ray photoelectron spectroscopy (XPS). Element mapping of PMCS (Figure 1c-g) indicated a homogeneous dispersion of $\mathrm{C}, \mathrm{N}, \mathrm{O}$, and $\mathrm{Zn}$ in the structure. The survey XPS spectrum of PMCS (Figure S5, Supporting Information) confirmed the presence of C, N, O, and $\mathrm{Zn}$, with atom ratios of $70.3 \%, 18.5 \%, 10.1 \%$, and $1.1 \%$, respectively. The high-resolution N1s XPS spectrum of PMCS was deconvoluted into three peaks at 398.2, 399.9, and $402.4 \mathrm{eV}$ (Figure 1h), assigned to pyridinic, pyrrolic, and graphitic N, respectively. ${ }^{[10 \mathrm{~b}, 23]}$ XAFS spectroscopy was used to further probe the local coordination environment of $\mathrm{Zn}$ atoms in PMCS. As shown in Figure 1i, the Zn K-edge of XANES of PMCS exhibits a near-edge structure very different to those of $\mathrm{Zn}$ foil and $\mathrm{ZnO}$, but similar to that of the tetraphenylporphyrinato zinc (porphyrin $\mathrm{Zn}$ ), indicating that the local coordination environment of Zn in PMCS is similar to that of the porphyrin Zn. This conclusion was further confirmed by the extended X-ray absorption fine structure (EXAFS) results. EXAFS spectra and their corresponding Fourier transforms with best fit curves are reported in Figure 1g and Figure S6 (Supporting Information), respectively. EXAFS spectra for PMCS were again very similar to that of the porphyrin $\mathrm{Zn}$. The numerical results of the best fits obtained after EXAFS data treatment, inter-atomic distances $(R)$, and coordination number $(N)$, are summarized in Table S1 (Supporting Information). The $\mathrm{Zn}-\mathrm{N}$ inter-atomic distance $(R)$ of PMCS of $2.03 \AA$ is identical to that of the porphyrin Zn. Coordination number (4.6) of PMCS was also similar to that of porphyrin $\mathrm{Zn} \mathrm{(4.0).} \mathrm{The} \mathrm{slight} \mathrm{difference} \mathrm{is} \mathrm{mainly} \mathrm{due} \mathrm{to}$ the imperfect porphyrin structure in PMCS, though the results strongly suggest that $\mathrm{Zn}$ centers in PMCS and the porphyrin Zn possess very similar local coordination environments. ${ }^{[24]}$ Results of Raman, element mapping, XPS, and XAFS analyses strongly suggest PMCS contain an abundance of porphyrin-like metal centers.

Light absorption in the NIR region is a prerequisite for NIR-induced PDT photosensitizers. The UV-vis-NIR absorption spectrum of PMCS in Figure 1k shows that it has a strong absorption in the NIR, indicating it has potential as an NIRinduced PDT photosensitizer. To establish the intrinsic photodynamic properties of PMCS, we measured the production of ROS using the dye dichlorofluorescein diacetate (DCFH-DA), which is oxidized to 2,7-dichlorofluorescein (DCF) (excitation/emission wavelength: $495 \mathrm{~nm} / 529 \mathrm{~nm}$ ) by ROS. ${ }^{[18]}$ A
PMCS-phosphate-buffered saline (PBS) solution and pure PBS were irradiated under an NIR laser $\left(808 \mathrm{~nm}, 1 \mathrm{~W} \mathrm{~cm}{ }^{-2}\right)$ for 10 min. Subsequently, DCFH-DA dye was added and the solution was left for $2.5 \mathrm{~h}$, followed by centrifugation. Absorbance signals (Figure S7a, Supporting Information) and emission signals (Figure S7b, Supporting Information) arising from the generation of ROS were detected. Time-dependent electron spin resonance (ESR) measurements for PMCS under whitelight irradiation $\left(50 \mu \mathrm{g} \mathrm{mL} \mathrm{mL}^{-1}\right)$ confirmed the generation of ${ }^{1} \mathrm{O}_{2}$ with 2,2,6,6-tetramethylpiperide (TEMP) as the trapping probe (Figure S8, Supporting Information). The ${ }^{1} \mathrm{O}_{2}$ generated by PMCS can be ascribed to electronic transfer to molecular oxygen from conjugated $\pi$-bond of porphyrin-like structures in the PMCS structure, analogous to a type II photodynamic reaction. ${ }^{[2]}$ We quantified the generation of ${ }^{1} \mathrm{O}_{2}$, the primary cytotoxic agent of tumor cells, using disodium 9,10-anthracendipropionic acid $\left(\mathrm{Na}_{2}\right.$-ADPA) as the ${ }^{1} \mathrm{O}_{2}$ trapping agent and ICG as the reference $\left({ }^{1} \mathrm{O}_{2}\right.$ quantum yield, $\left.\Phi_{\text {ICG }}=0.0020\right)$ (Figure 2a,b). ${ }^{[25]}$ The analysis used NIR absorption at $808 \mathrm{~nm}$. Figure 2c,d showed that the absorbance intensity of $\mathrm{Na}_{2}$-ADPA gradually decreased with time under NIR light $\left(1 \mathrm{~W} \mathrm{~cm}^{-2}\right)$, indicating that $\mathrm{Na}_{2}$-ADPA was photo-bleached by ${ }^{1} \mathrm{O}_{2}$ produced by PMCS and ICG. The rate constant for $\mathrm{Na}_{2}$-ADPA decomposition by PMCS was $\approx 0.01671 \mathrm{~min}^{-1}$, slightly larger than that of ICG $\left(\approx 0.01441 \mathrm{~min}^{-1}\right.$ ) (Figure 2e,f, and Figure S9, Supporting Information). Furthermore, the ${ }^{1} \mathrm{O}_{2}$ quantum yield of PMCS was calculated to be $\approx 0.0023$ (see the Supporting Information for more details), which was slight higher than the value of ICG $\left(\Phi_{\text {ICG }}=0.0020\right)$. Results imply that PMCS are excellent sensitizers for PDT.

Materials with strong NIR absorption are generally considered to be good photothermal agents for PTT. ${ }^{[26]}$ Accordingly, the photothermal properties of PMCS were investigated. We measured the temperature increase of PMCS aqueous dispersions of different concentration under $808 \mathrm{~nm}$ NIR irradiation $\left(1 \mathrm{~W} \mathrm{~cm} \mathrm{~cm}^{-2}\right.$ for $10 \mathrm{~min})$. As shown in Figure 3a,b, the temperature of PMCS aqueous dispersions increased rapidly with irradiation time and also with PMCS concentration. In contrast, the temperature of pure water increased by only $2.32{ }^{\circ} \mathrm{C}$ after NIR irradiation for $10 \mathrm{~min}$. The result was confirmed by infrared (IR) thermal imaging of water and a PMCS aqueous dispersion $\left(100 \mu \mathrm{g} \mathrm{mL} \mathrm{m}^{-1}\right)$ as a function of NIR irradiation time (Figure 3c). Further experiments were conducted in which PMCS $\left(50 \mu \mathrm{g} \mathrm{mL}^{-1}\right)$ was irradiated by $808 \mathrm{~nm}$ NIR at $1 \mathrm{~W} \mathrm{~cm}^{-2}$ for five cycles $(2 \mathrm{~min}$ irradiation followed by a 2 min cooling period) (Figure 3d), which indicated that the pulsed irradiation did not significantly change photothermal performance of these nanoparticles. No noticeable particle aggregation or change of morphology was observed after irradiation for $10 \mathrm{~min}$ (Figure S10, Supporting Information), suggesting the dispersions have good stability. Additionally, the photothermal conversion efficiency $(\eta)$ was calculated as $\approx 33.0 \%$, much higher than most other photothermal agents such as Au nanorods (21.0\%), ${ }^{[17]} \mathrm{Au}$ shells $(13.0 \%),{ }^{[17]} \mathrm{Bi}_{2} \mathrm{~S}_{3}$ nanorods (28.1\%), ${ }^{[27]}$ and $\mathrm{Cu}_{2-x} \mathrm{~S}$ nanoparticles $(16.3 \%)^{[18]}$ (Figure S11, Supporting Information). The strong photothermal conversion capacity and excellent photostability of PMCS suggest that they have great potential as photothermal agents.

To investigate the in vitro toxicity and phototoxicity effects of PMCS for biomedical applications, the potential toxicity of 
a)

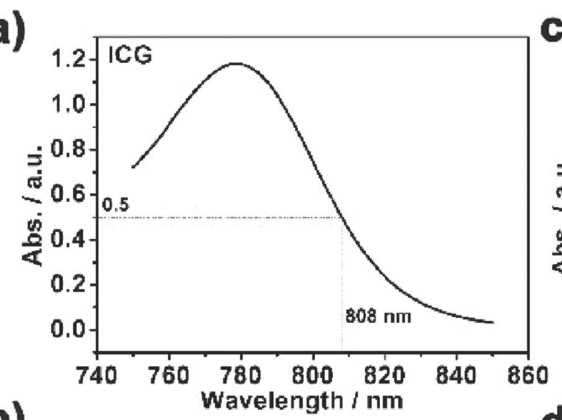

b)

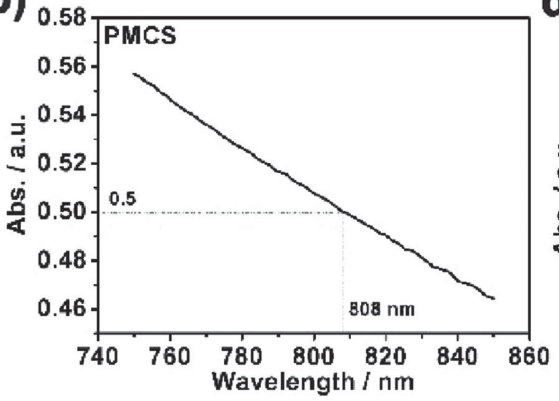

c)

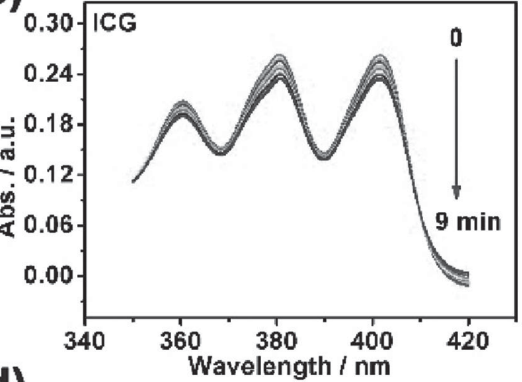

d)

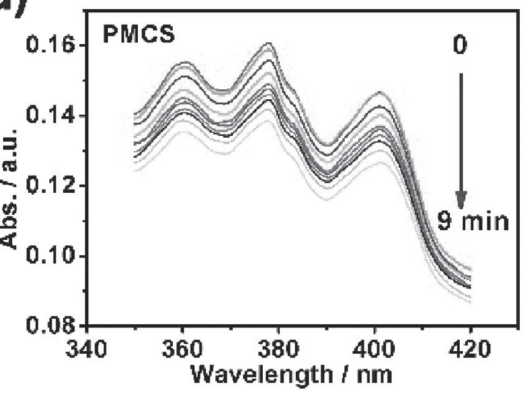

e)

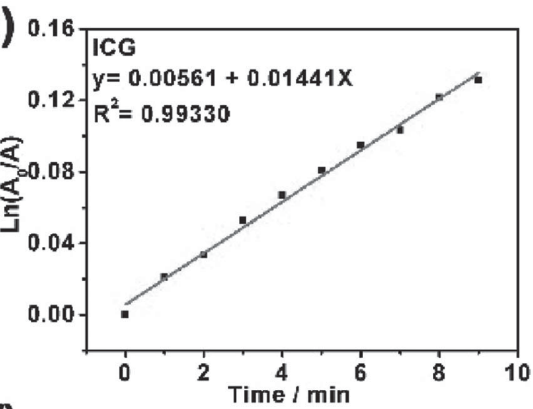

f) 0.1

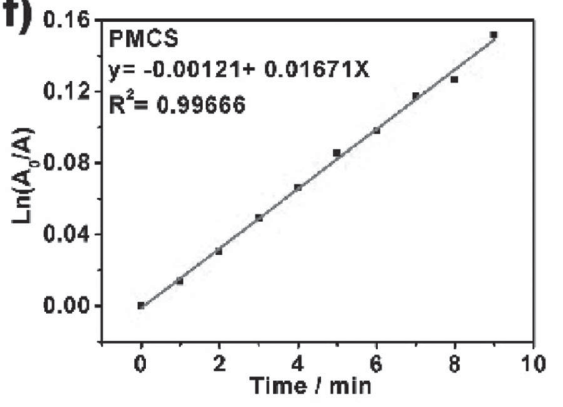

Figure 2. Quantitative measurement of singlet oxygen quantum yield generated by PMCS. ICG was used as a comparative reference. a,b) UV-vis-NIR spectra for ICG and PMCS, respectively. $\mathrm{c}, \mathrm{d}$ ) Time-dependent photo-degradation of $\mathrm{Na}_{2}-\mathrm{ADPA}_{\text {caused by }}{ }^{\mathrm{O}} \mathrm{O}_{2}$ generated by ICG and PMCS under NIR irradiation $\left(808 \mathrm{~nm}, 1 \mathrm{~W} \mathrm{~cm}{ }^{-2}, 9 \mathrm{~min}\right)$. e,f) Rate constants for $\mathrm{Na}_{2}$-ADPA decomposition in the presence of ICG and PMCS, respectively.

PMCS was first measured at different concentrations $(80,40$, $20,10,5,2.5,1.25$, and $0.625 \mu \mathrm{g} \mathrm{mL} \mathrm{m}^{-1}$ ) by incubation with HepG2 cells for $24 \mathrm{~h}$ using a Cell Counting Kit-8 (CCK-8) assay. As Figure 4a shows, no significant toxicity was observed at PMCS concentrations ranging from 0.625 to $80 \mu \mathrm{g} \mathrm{mL}^{-1}$. These results illustrate that at low concentrations PMCS is

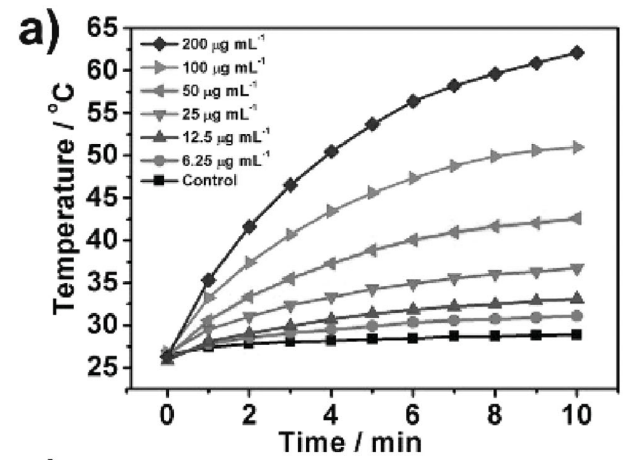

c)

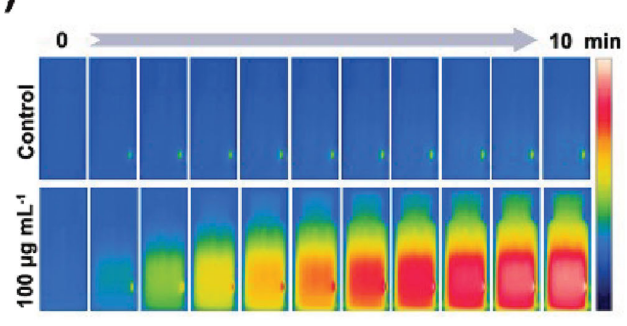

b)

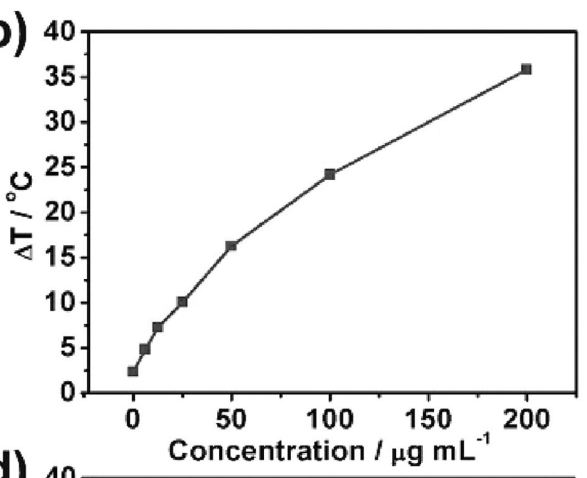

d)

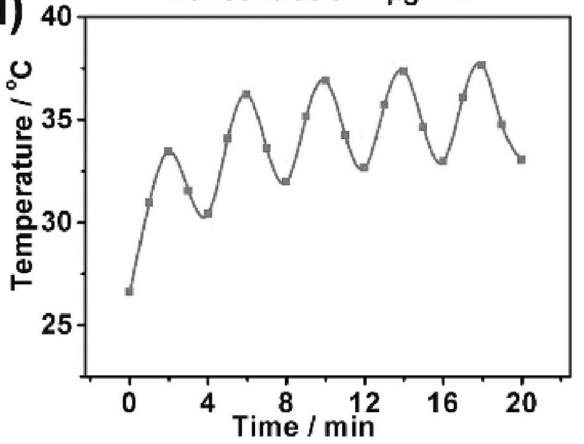

Figure 3. a) Temperature elevation of water and PMCS aqueous dispersions of different concentration $\left(6.25,12.5,25,50,100\right.$, and $\left.200 \mu \mathrm{g} \mathrm{mL} \mathrm{L}^{-1}\right) \mathrm{under}$ $808 \mathrm{~nm}$ laser irradiation with a power density of $1 \mathrm{~W} \mathrm{~cm}^{-2}$ for $10 \mathrm{~min}$. b) Plot temperature change $(\Delta T)$ over a period of 10 min versus the concentration

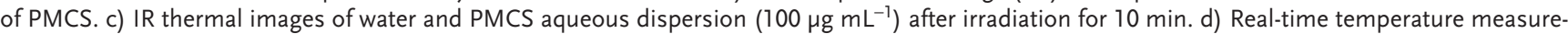
ment of PMCS aqueous dispersion $\left(50 \mu \mathrm{g} \mathrm{mL}^{-1}, 1 \mathrm{~mL}\right)$ under $808 \mathrm{~nm}$ NIR light irradiation with a power density of $1 \mathrm{~W} \mathrm{~cm}^{-2}$, for five cycles. Each cycle consisted of 2 min irradiation followed by a 2 min cooling phase. 

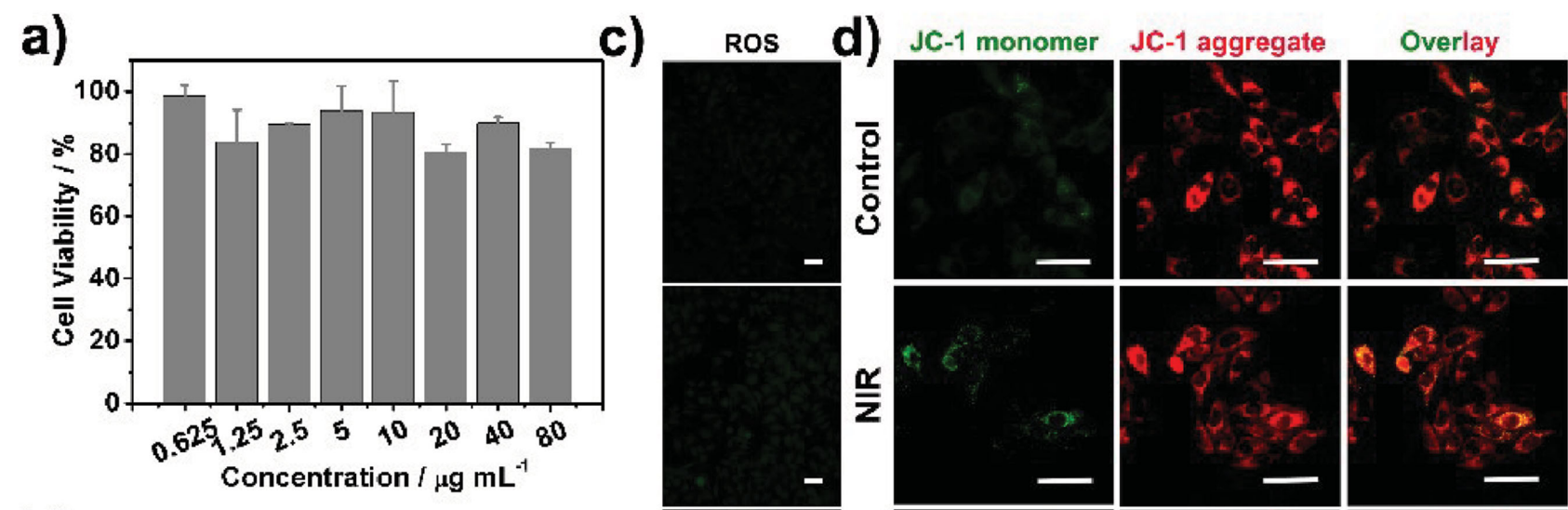

b)
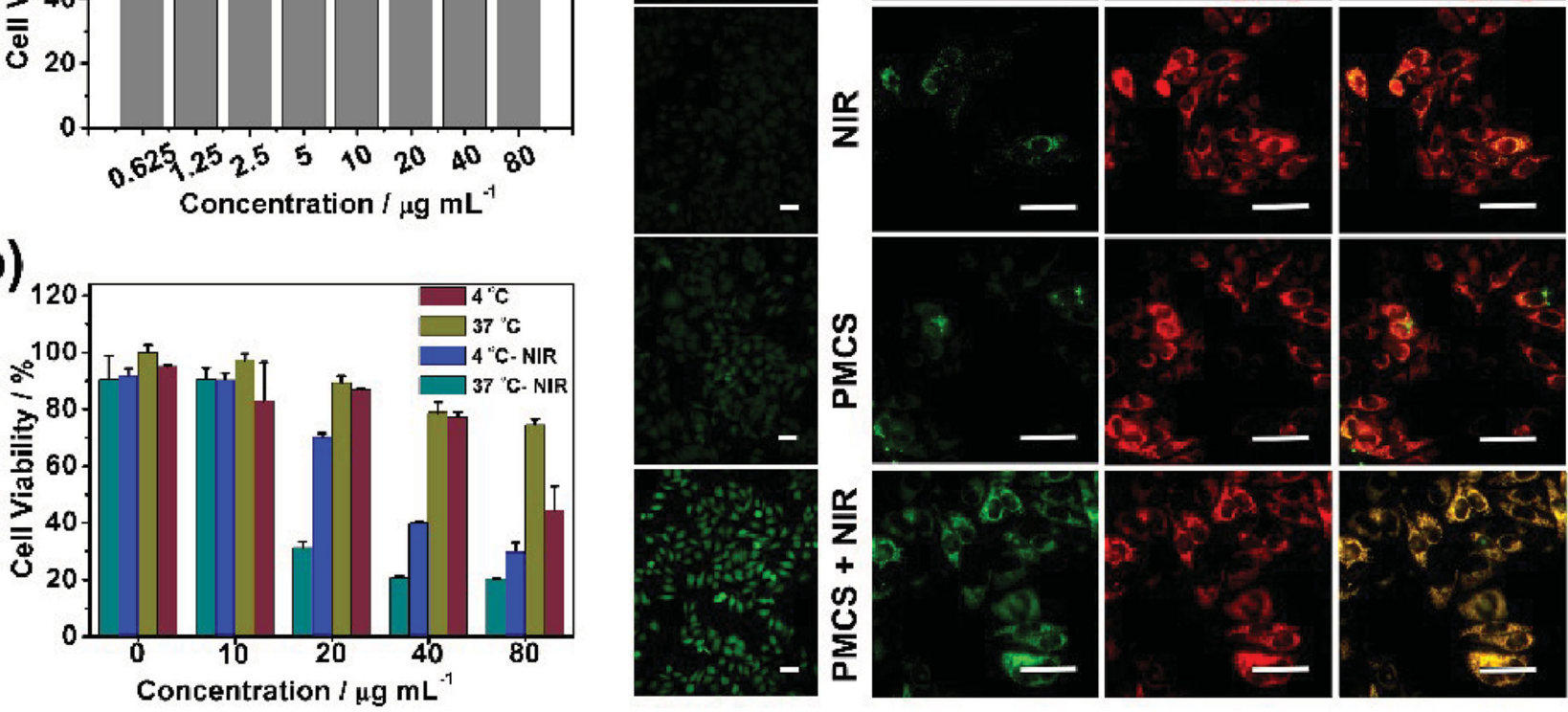

Figure 4. a) Cell viability of HepG2 cells incubated with PMCS for $24 \mathrm{~h}$ at different concentrations $\left(80,40,20,10,5,2.5,1.25\right.$, and $\left.0.625 \mu \mathrm{g} \mathrm{mL} \mathrm{L}^{-1}\right)$. b) Cell viability of HepG2 cells incubated with PMCS at different concentrations $\left(80,40,20,10 \mu \mathrm{g} \mathrm{mL}^{-1}\right)$ for $24 \mathrm{~h}$ with or without $808 \mathrm{~nm}$ irradiation $\left(1 \mathrm{~W} \mathrm{~cm}^{-2}\right)$ for 3 min at 4 and $37^{\circ} \mathrm{C}$, respectively. c,d) ROS levels and MMP measured by JC-1 staining of HepC2 cells after the co-incubated with or without PMCS for $6 \mathrm{~h}$ at different groups: control groups, NIR groups $\left(808 \mathrm{~nm}, 0.6 \mathrm{~W} \mathrm{~cm}^{-2}, 3 \mathrm{~min}\right), \mathrm{PMCS}\left(25 \mu \mathrm{g} \mathrm{mL}^{-1}\right)$, and PMCS $+\mathrm{NIR} \mathrm{groups}\left(25 \mu \mathrm{g} \mathrm{mL} \mathrm{L}^{-1}, 808 \mathrm{~nm}\right.$, $\left.0.6 \mathrm{~W} \mathrm{~cm}^{-2}, 3 \mathrm{~min}\right)$, respectively. The scale bar in all images is $50 \mu \mathrm{m}$.

biocompatible, similar to observations for other carbon materials. ${ }^{[28]}$ However, the cell viability decreased rapidly at concentrations above $20 \mu \mathrm{g} \mathrm{mL} \mathrm{mL}^{-1}$ under $808 \mathrm{~nm}$ laser irradiation $\left(1 \mathrm{~W} \mathrm{~cm}{ }^{-2}, 3 \mathrm{~min}\right)$ at 4 and $37^{\circ} \mathrm{C}$ (Figure $\left.4 \mathrm{~b}\right)$. Fluorescence images (Figure S12, Supporting Information) demonstrate that the cells were killed (red color) within the irradiation area, while the cells outside this region were alive (green color). The data confirmed efficient killing of cancer cells by PMCS under NIR irradiation. Cell viability under NIR irradiation at $37{ }^{\circ} \mathrm{C}$ was about half that at $4{ }^{\circ} \mathrm{C}$ (Figure $4 \mathrm{~b}$ ). This illustrates that at $37^{\circ} \mathrm{C}$, localized heating and ROS generated by the action of NIR irradiation on PMCS are responsible for cell apoptosis via combination of PTT and PDT. ${ }^{[29]}$ For the groups at $4{ }^{\circ} \mathrm{C}$, cellular damage was predominantly a PDT effect. ROS generation by PMCS under NIR irradiation in cancer cells was evaluated via the fluorescent probe, DCFH-DA. The results in Figure 4c and Figure S13a (Supporting Information) show that the fluorescence signal in experiment groups (PMCS+NIR) is higher than that observed in the other groups, especially the control group, consistent with findings of the in vitro treatment and photo-degradation experiments. Furthermore, oxidative stress induced by excessive ROS can cause mitochondrial dysfunction. ${ }^{[30]}$ Thus, we also measured the change in mitochondrial membrane potential (MMP), an important indicator of mitochondrial dysfunction, by the 5,5',6,6'-tetrachloro1,1',3,3'-tetraethyl-imidacarbocyanine (JC-1) assay. For normal mitochondria, fluorescent red JC-aggregates are produced by JC-1 gathering in mitochondria. For damaged mitochondria, MMP decreases due to fluorescent green JC-monomer generation by re-dispersion of red JC-aggregates in the cytoplasm. Figure 4d and Figure S13b (Supporting Information) reveal that cells treated by PMCS and NIR irradiation have a low red/green fluorescence ratio, indicating a loss of MMP and mitochondrial dysfunction induced by ROS. Due to their strong NIR absorption, carbon-based nanomaterials have been widely researched as contrast agents in PA imaging with improved tissue penetration and high spatial resolution. ${ }^{[31]}$ Here, it was found that the in vitro PA signal intensity of PMCS-PBS $\left(100 \mu \mathrm{g} \mathrm{mL} \mathrm{L}^{-1}\right)$ was highly wavelength-dependent (Figure 5a). Further, after PMCS injection, in vivo PA imaging signals were also detected in the tumor region at wavelengths of 730, 760, and $800 \mathrm{~nm}$. (Figure 5b). ${ }^{[32]}$ Therefore, both in vitro and in vivo tests indicated that PMCS is effective as a contrast agent for PA imaging at tumor sites, demonstrating its potential for conformal cancer therapy.

Encouraged by the positive PTT/PDT performance of PMCS under NIR irradiation, we verified an in vivo combination therapy effect using CD-1 nude mice bearing HepG2 tumors. The nude mice bearing HepG2 tumor were injected intratumorally (i.t.) with a PMCS-PBS solution $\left(2 \mathrm{mg} \mathrm{mL}^{-1}, 150 \mu \mathrm{L}\right)$. We monitored the temperature variation of the tumor location exposed to $808 \mathrm{~nm}$ NIR laser $\left(0.6 \mathrm{~W} \mathrm{~cm}^{-2}\right)$ using an IR 

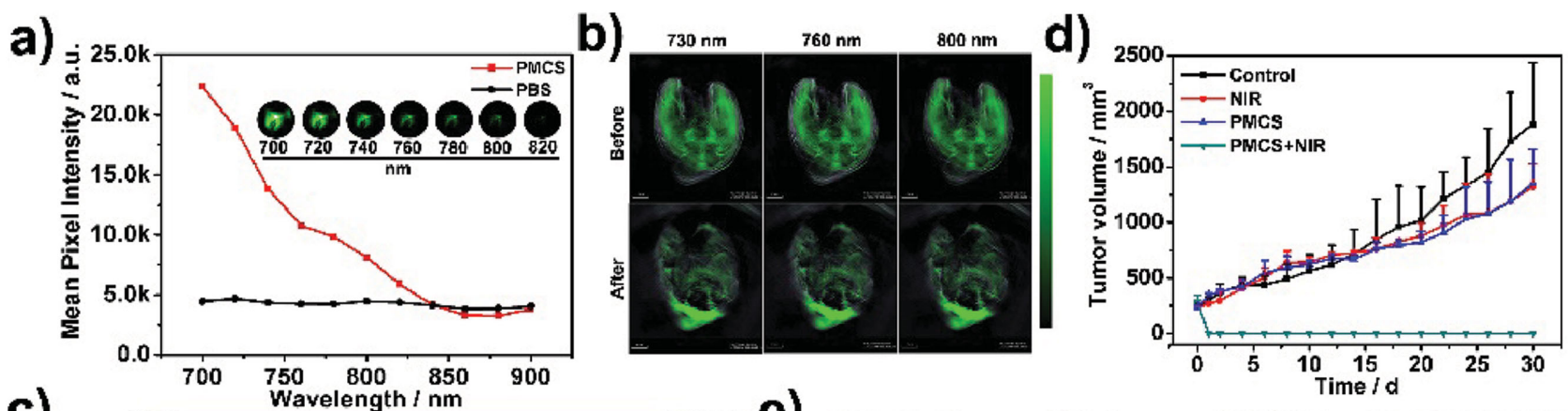

c)

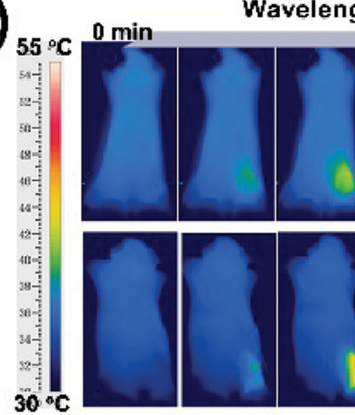

$3 \min e)$

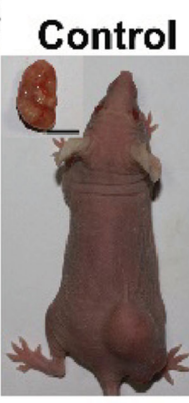

f)
옹
은

Heart
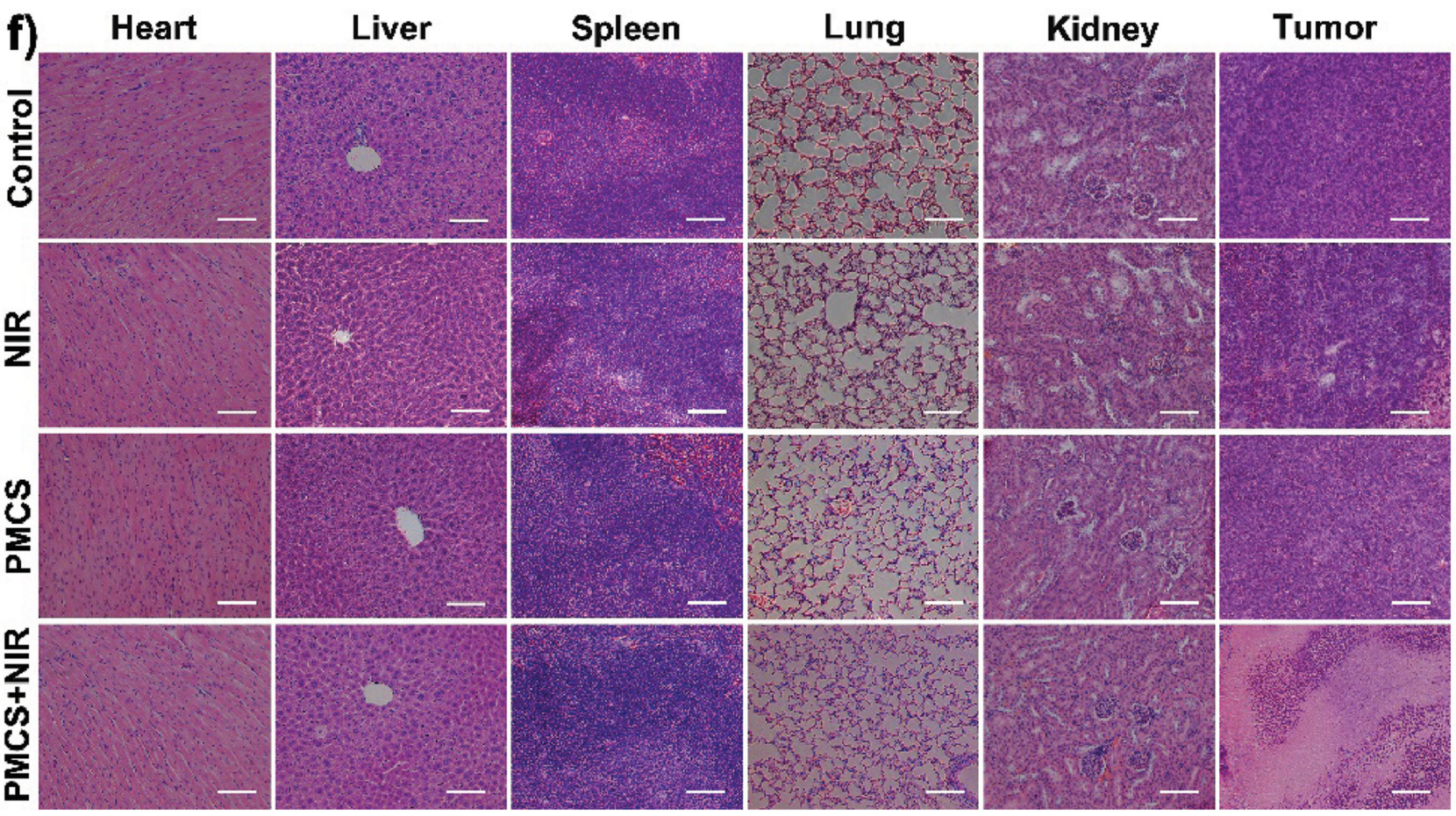

NIR PMCS

PMCS+NIR

Figure 5. In vitro/vivo PA and IR thermal imaging and in vivo combination therapy by PMCS. a,b) PA signal intensity of PMCS-PBS (100 $\mu \mathrm{g} \mathrm{mL}^{-1}$ ) in vitro and HepC2-bearing CD-1 nude mice i.t. injection by PMCS-PBS $\left(2 \mathrm{mg} \mathrm{mL}^{-1}, 150 \mu \mathrm{L}\right)$ in vivo at various wavelength. c) IR thermal imaging by HepC2-bearing CD-1 nude mice i.t. injected by PMCS $(150 \mu \mathrm{L})$ in $2 \mathrm{mg} \mathrm{mL}^{-1}$ recorded by IR thermal camera. The tumor location was irradiated by $808 \mathrm{~nm}$ NIR laser at $0.6 \mathrm{~W} \mathrm{~cm}{ }^{-2}$ for 3 min. d) Tumor volume curve of CD-1 nude mice of different groups during treatment period. e) Photographs of CD-1 nude mice and tumor collected from control, NIR, PMCS, and PMCS+NIR groups over $30 \mathrm{~d}$. Two out of three tumors were completely eliminated in the PMCS+NIR group. The scale bar in all images is $1 \mathrm{~cm}$. f) H\&E-stained heart, liver, spleen, lung, kidney, and tumor slices obtained from control, NIR, PMCS, and PMCS+NIR groups. The scale bar in all images is $50 \mu \mathrm{m}$.

thermal camera. In Figure 5c, the tumor surface temperatures treated with PMCS under NIR irradiation rapidly reached $\approx 57.6{ }^{\circ} \mathrm{C}$ (in $\approx 3 \mathrm{~min}$ ), which was sufficient for tumor ablation. In contrast, the temperature around the tumor treated with PBS increased only slightly (by about $5.5^{\circ} \mathrm{C}$ ). This result confirmed effective in vivo tumor destruction mediated by the high photothermal conversion efficiency of PMCS. Next, we measured the in vivo therapeutic effect of PMCS (Figure 5d). The nude mice bearing HepG2 tumor was randomly divided into four groups: i) control group; ii) NIR group $\left(0.6 \mathrm{~W} \mathrm{~cm}{ }^{-2}\right.$, 
$3 \mathrm{~min}$ ); iii) PMCS group (20 $\left.\mathrm{mg} \mathrm{kg}^{-1}\right)$; and iv) PMCS+NIR group (20 mg kg-1, $0.6 \mathrm{~W} \mathrm{~cm}{ }^{-2}, 3 \mathrm{~min}$ ). After $1 \mathrm{~d}$, black scars in the tumor site were observed for the PMCS+NIR group, with two out of three tumors having completely disappeared over the treatment period (Figure 5e). The NIR group and PMCS group showed reduced tumor growth rates compared with the control group, though no obvious tumor suppression. The mice treated with PMCS showed no body weight loss during the observation period (Figure S14, Supporting Information) or no obvious inflammation. Further, no tumor cell necrosis or apoptosis was found in tissue slices of the PMCS-treated mice, indicating that there was no significant toxicity or side effects in the treatment group (Figure 5f). The intrinsic photothermal effects and photodynamic effects of PMCS, combined with IR and PA imaging, suggest that PMCS has great potential for effective conformal cancer therapy.

In addition to the above experiments, we investigated the in vitro/vivo potential toxicity of PMCS for bioapplications. Figure S15 (Supporting Information) shows the hemolytic behavior of PMCS, revealing a maximum hemolysis rate of $3.16 \%$ in a concentration of $250 \mu \mathrm{g} \mathrm{mL} \mathrm{m}^{-1}$. The inset images show results for the control group (water). According to the in vivo toxicity method recommended by the Organization for Economic Cooperation and Development (OECD, guideline 425), we evaluated the acute toxicity of PMCS. Doses of 400 , 200, 150, 100, 50, 25, and $12.5 \mathrm{mg} \mathrm{kg}^{-1}$ were intravenously injected, and the body weight change of ICR mice recorded. Mice administered with $400 \mathrm{mg} \mathrm{kg}^{-1}$ PMCS died within 5 min. Mice administered with 200, 150, 100, 50, 25, and $12.5 \mathrm{mg} \mathrm{kg}^{-1}$ PMCS remained alive during the whole observation period. The body weight of ICR mice was not significantly altered by the treatments (Figure S16, Supporting Information). After $15 \mathrm{~d}$, the mice were sacrificed and blood samples collected for hematology and biochemistry analysis.

In Figure S17a (Supporting Information), the main liver function markers containing alanine aminotransferase (ALT) and aspartate aminotransferase (AST) and kidney function markers containing blood urea nitrogen (BUN) and creatinine (CREA) showed no obvious difference with the control group, indicating negligible hepatic and kidney disorders resulting from administering ICR mice with PMCS from 12.5 to $200 \mathrm{mg} \mathrm{kg}^{-1}$. In the hematology analysis including hematocrit (HCT), mean corpuscular volume (MCV), mean corpuscular hemoglobin $(\mathrm{MCH})$, mean corpuscular hemoglobin concentration (MCHC), hemoglobin (HGB), red blood cells (RBC), platelets (PLT), and white blood cells (WBC), no obvious abnormal parameters were detected in the PMCS-injection group (Figure S17b, Supporting Information). Therefore, PMCS had low toxicity and favorable biocompatibility in vivo, which make it suitable for biomedical applications.

In summary, we have demonstrated for the first time that PMCS can be used as stable photosensitizers and photothermal agents in phototherapy. Under $808 \mathrm{~nm}$ laser irradiation, PMCS demonstrate good stability and highly photothermal conversion efficiencies, and afford a similar singlet oxygen quantum yield to ICG (a common NIR dye/photosensitizer). Acute toxicity studies established that PEGylated PMCS has good biocompatibility both in vivo or in vitro. PMCS caused high tumor cell necrosis/apoptosis under NIR laser irradiation. Furthermore,
PMCS achieved excellent IR and PA contrast performance for HepG2-bearing mice, allowing real-time monitoring of therapeutic processes and image-guided precise conformal therapy. Most importantly, PTT/PDT synergetic therapy can result in complete tumor regression for tumor-bearing nude mice after $808 \mathrm{~nm}$ laser treatment. Results suggest that carbon nanospheres containing porphyrin-like metal centers could play an important role in future cancer treatment.

\section{Experimental Section}

Materials: $\mathrm{Zn}\left(\mathrm{NO}_{3}\right)_{2} \cdot 6 \mathrm{H}_{2} \mathrm{O}, 2$-methylimidazole, cetyltrimethylammonium bromide (CTAB), PEG-vitamin E, and tetraethyl orthosilicate (TEOS) were obtained from Sigma. ICG and ADPA were purchased from ENERGY. Hematoxylin and eosin (H\&E) were purchased from Beijing Solarbio Science \&Technology (China). All reagents used in this work were analytical reagents (A.R.) and used without any further purification.

Synthesis of ZIF-8 Nanoparticles: A solution of $\mathrm{Zn}\left(\mathrm{NO}_{3}\right)_{2} \cdot 6 \mathrm{H}_{2} \mathrm{O}(32 \mathrm{mmol}$ in $500 \mathrm{~mL} \mathrm{CH} \mathrm{CH}_{3}$ ) was poured into a solution containing $135 \mathrm{mmol}$ 2-methylimidazole and $0.3 \mathrm{mmol}$ CTAB in methanol $(400 \mathrm{~mL})$, and the resulting solution stirred for $2 \mathrm{~h}$ at room temperature. The white solid precipitate was separated by centrifugation and washed with methanol.

Synthesis of ZIF-8@mSiO 2 Core@Shell Nanoparticles: ZIF-8 was dispersed in $240 \mathrm{~mL}$ of a 10 vol\% methanol solution which had already been adjusted to $\mathrm{pH} 11$ with $\mathrm{NaOH}$, and then $6 \mathrm{~mL}$ of an aqueous CTAB $\left(0.068 \mathrm{~mol} \mathrm{~L}^{-1}\right)$ solution was added. TEOS $(1.2 \mathrm{~mL})$ was then added dropwise into the above solution, and the resulting dispersion was stirred for $0.5 \mathrm{~h}$. The resulting core-shell nanoparticles were separated by centrifugation and washed with ethanol.

Synthesis of Porphyrin-Like Mesoporous Carbon Nanospheres (PMCS): The ZIF-8@ $\mathrm{mSiO}_{2}$ core@shell sample was pyrolyzed at $800{ }^{\circ} \mathrm{C}$ for $2 \mathrm{~h}$ under flowing $\mathrm{N}_{2}$, and then allowed to cool slowly to room temperature. The pyrolyzed sample was then etched with $4 \mathrm{M} \mathrm{NaOH}$ solution to remove the $\mathrm{mSiO}_{2}$ shell, followed by centrifugation and washing with deionized water several times until the supernatant was neutral. Then, PMCS were modified by mixing with PEG-VE $(1 \mathrm{kD})$ solution followed by centrifugation and washing with deionized water two times.

Characterization: A JEM-2100 transmission electron microscope (TEM) operating at $200 \mathrm{kV}$ was used to characterize the morphology and structure of PMCS. High-angle annular dark-field scanning TEM (HAADF-STEM)-energy-dispersive X-ray (EDX) (Tecnal G2 F20 U-Twin) was used to characterize PMCS morphology and analyze the bulk distribution of $\mathrm{C}, \mathrm{Zn}, \mathrm{O}$, and N. XRD pattern was taken on a Bruker D8 Focus X-ray diffractometer with $\mathrm{Cu} K \alpha$ radiation $(\lambda=1.5405 \AA)$. Porphyrin-like structure in the PMCS was analyzed by XPS and XAFS spectroscopy. XAFS measurements were performed at the IW1B beamline of Beijing Synchrotron Radiation Facility. Standard EXAFS data reduction procedures were undertaken using the program package IFEFFIT (Newville 2001). The $\mathrm{ZnO}$ spectrum was used to determine an empirical $\mathrm{S} 02$ value (0.87), which was then fixed for the fitting of all subsequent samples. UV-vis-NIR spectra for PMCS were collected on either a JASCO UV-vis 570 or a Cary 5000 UV-vis-NIR spectrometer. Raman spectra were taken on an inVia-Reflex system. $\mathrm{N}_{2}$ physisorption data were used to measure the specific surface area, pore size, and pore volume of PMCS (Quadrasorb SI-MP). ${ }^{1} \mathrm{O}_{2}$ was quantified by an ESR spectrometer (E 500E).

In Vitro ROS Measurements of PMCS: ROS Detection by DCFH-DA: PMCS-PBS solution $\left(50 \mu \mathrm{g} \mathrm{mL} \mathrm{m}^{-1}, 1 \mathrm{~mL}\right)$ was irradiated at $808 \mathrm{~nm}$ for $10 \mathrm{~min}$ at a power density of $1 \mathrm{~W} \mathrm{~cm}$. Then, $250 \mathrm{mmol}$ of DCFH-DA $\left(6 \mathrm{mg} \mathrm{mL}^{-1}\right)$ was added to the samples, followed by incubation for $2.5 \mathrm{~h}$. The supernatant was collected by centrifugation ( $5 \mathrm{~min}, 9000 \mathrm{rpm}$ ), and analyzed by UV-vis and fluorescence spectroscopy.

Singlet Oxygen Measurements by ESR: ${ }^{1} \mathrm{O}_{2}$ generation was evaluated by ESR using the TEMP spin-trapping adduct, which gives rise to a 
characteristic triplet ESR signal. Spectra of spin trapped ${ }^{1} \mathrm{O}_{2}$ were obtained by mixing $10 \mu \mathrm{L}$ TEMP with $50 \mu \mathrm{L}$ PMCS solution at $50 \mu \mathrm{g} \mathrm{mL}^{-1}$. Samples were injected into custom-made quartz capillaries for ESR analysis and then the cavity of the ESR spectrometer was irradiated by white light source for 2 min.

Singlet Oxygen Quantum-Yield Measurements: The $\mathrm{Na}_{2}$-ADPA was used as ${ }^{1} \mathrm{O}_{2}$ trapping agent, with ICG used as reference $\left({ }^{1} \mathrm{O}_{2}\right.$ quantum yield $\left.\Phi_{\text {ICC }} 0.0020\right)$. In the experiment, the UV absorption at $808 \mathrm{~nm}$ of PMCS and ICG was adjusted to $\approx 0.5$ OD to avoid inner-filter effects. Then, $\mathrm{Na}_{2}$-ADPA solution $\left(60 \mu \mathrm{L}, 1 \mathrm{mg} \mathrm{mL}^{-1}\right)$ was added to the PMCS solution $(1.5 \mathrm{~mL})$ with NIR laser light irradiation $\left(808 \mathrm{~nm}, 1 \mathrm{~W} \mathrm{~cm}{ }^{-2}\right)$ for $9 \mathrm{~min}$. The decomposition rate of $\mathrm{Na}_{2}$-ADPA by PMCS and ICG was recorded at various irradiation times, and quantified by the absorbance intensity change of $\mathrm{Na}_{2}$-ADPA at $378 \mathrm{~nm}$. The detailed calculation of ${ }^{1} \mathrm{O}_{2}$ quantum yield is descried in the Supporting Information.

In Vitro Photothermal Measurement: The photothermal conversion efficiency of PMCS at different concentrations $(6.25,12.5,25,50,100$, and $200 \mu \mathrm{g} \mathrm{mL}^{-1}$ ) was determined by continuous wave (CW) GCSLS-05007 semiconductor laser device (Daheng New Epoch Technology, Inc., Beijing, China) operating at $808 \mathrm{~nm}$ and a power density of $1 \mathrm{~W} \mathrm{~cm}$. A vial containing PMCS solution $(1 \mathrm{~mL})$ was irradiated by NIR laser light transferred by an optical fiber. The temperature change of the solution was recorded by a PT-3S thermo-detector (Optex Co., Ltd., Japan). The detailed protocol is described in the Supporting Information.

For real-time measurements, PMCS $\left(1 \mathrm{~mL}, 50 \mu \mathrm{g} \mathrm{mL}^{-1}\right)$ was irradiated by $1 \mathrm{~W} \mathrm{~cm}-2,808 \mathrm{~nm}$ NIR light for five cycles. Each cycle consisted of 2 min irradiation followed by a 2 min natural cooling. Temperature data points were collected at 1 min intervals.

Hemolysis Assay: A hemolysis assay was carried out to evaluate the cytotoxicity of PMCS in vitro. Rabbit heart blood $(5 \mathrm{~mL})$ was stabilized by ethylenediamine tetraacetic acid (EDTA) $(0.2 \mathrm{~mL})$, an anticoagulant agent. Then red blood cells (RBCs) were obtained from the rabbit heart blood by centrifugation and washing with PBS (2\%). $0.5 \mathrm{~mL}$ of the RBC solution was then mixed with $0.5 \mathrm{~mL}$ PMCS PBS solution at different concentrations $\left(15.63,31.25,62.5,125\right.$, and $\left.250 \mu \mathrm{g} \mathrm{mL}^{-1}\right)$. Water and PBS were used as the positive and negative controls, respectively. All samples were mixed gently and kept at room temperature for $3 \mathrm{~h}$. The absorbance of each supernatant, obtained by centrifugation, was measured at $570 \mathrm{~nm}$ on a JASCO UV-vis photospectrometer. The hemolysis ratio was calculated by using the formula: hemolysis ratio $=$ (sample absorbance - negative control absorbance)/(positive control absorbance - negative control absorbance) $\times 100$.

Cellular Experiments: The human liver carcinoma cell line (HepG2 cells) was originally obtained from the American Type Culture Collection (ATCC), and was cultured in a high-glucose Dulbecco's modified Eagle medium (DMEM) at $37^{\circ} \mathrm{C}$ and a $5 \% \mathrm{CO}_{2}$ atmosphere.

In Vitro Cytotoxicity: The in vitro cytotoxicity of PMCS was evaluated by CCK-8 assay. HepC2 was seeded in 96 -well plates at $10^{4}$ well $^{-1}$ and incubated for $24 \mathrm{~h}$. Then, PMCS solution at different concentrations $(80$, $40,20,10,5,2.5,1.25$, and $0.625 \mathrm{\mu g} \mathrm{mL}^{-1}$ ) was added into 96 -well plates and incubated for $24 \mathrm{~h}$. The cell viability was detected by CCK-8 assay following a standard protocol.

For in vitro photothermal/photodynamic cell cytotoxicity experiments, HepG2 cells were incubated with PMCS at different concentrations (80, 40,20 , and $10 \mu \mathrm{g} \mathrm{mL} \mathrm{L}^{-1}$ ) for $24 \mathrm{~h}$. The cells were irradiated by NIR laser light at a power density of $1 \mathrm{~W} \mathrm{~cm}-2$ for 3 min at 4 or $37^{\circ} \mathrm{C}$, and incubated for $24 \mathrm{~h}$. The in vitro photothermal/photodynamic combination effect was determined by CCK- 8 assay. For the co-staining of HepC2 cells by calcein AM/PI, HepG2 cells were incubated with PMCS $\left(25 \mu \mathrm{g} \mathrm{mL} \mathrm{L}^{-1}\right)$ for $6 \mathrm{~h}$ in culture dishes. Then, the HepG2 cells were co-stained with calcein AM/PI for $15 \mathrm{~min}$ after $808 \mathrm{~nm}$ laser irradiation $(0.6 \mathrm{~W} \mathrm{~cm}$, $3 \mathrm{~min}$ ). Green color stained by calcein $\mathrm{AM}$ and red color stained by PI represented live and dead cells, respectively.

Fluorescent Imaging: For determination of ROS levels via fluorescent imaging, HepC2 cells were co-incubated with or without PMCS for $6 \mathrm{~h}$ in four different groups: control group, NIR group $\left(808 \mathrm{~nm}, 0.6 \mathrm{~W} \mathrm{~cm}{ }^{-2}\right.$, $3 \mathrm{~min})$, PMCS group $\left(25 \mu \mathrm{g} \mathrm{mL}^{-1}\right)$, and PMCS+NIR group $\left(25 \mu \mathrm{g} \mathrm{mL} \mathrm{L}^{-1}\right.$, $\left.808 \mathrm{~nm}, 0.6 \mathrm{~W} \mathrm{~cm}^{-2}, 3 \mathrm{~min}\right)$, respectively. Then, the fluorescent dye,
DCFH-DA $\left(10 \mu \mathrm{mol} \mathrm{L} \mathrm{L}^{-1}\right)$, was added and co-incubated for $50 \mathrm{~min}$ at $37{ }^{\circ} \mathrm{C}$. The NIR and PMCS+NIR groups were irradiated by $808 \mathrm{~nm}$ NIR laser light $\left(0.6 \mathrm{~W} \mathrm{~cm} \mathrm{~cm}^{-2}, 3 \mathrm{~min}\right)$ after replacing the medium with PBS. ROS level was determined by fluorescence microscopy. For the JC-1 assay, the PMCS were co-incubated with cells for $6 \mathrm{~h}$ in different groups: control groups, NIR groups ( $\left.808 \mathrm{~nm}, 0.6 \mathrm{~W} \mathrm{~cm}^{-2}, 3 \mathrm{~min}\right)$, PMCS $\left(25 \mu \mathrm{g} \mathrm{mL}^{-1}\right)$, and PMCS+NIR groups $\left(25 \mu \mathrm{g} \mathrm{mL}^{-1}, 808 \mathrm{~nm}, 0.6 \mathrm{~W} \mathrm{~cm}{ }^{-2}\right.$, $3 \mathrm{~min}$ ). The cells were stained with JC-1 for $30 \mathrm{~min}$ before washing with PBS. Then, the mitochondrial damage/disruption was detected by fluorescence microscopy.

Animal Model: ICR mice and CD-1 nude mice (aged 4-5 weeks) were purchased from Vital River Laboratory Animal Technology Co. Ltd.) and used in compliance with a local ethics committee. The CD-1 nude mice were injected subcutaneously with serum-free DMEM of HepG2 cells $\left(4 \times 10^{6}, 200 \mu \mathrm{L}\right)$.

Multimodal Imaging: For in vitro $\mathrm{IR}$ thermal imaging, $1 \mathrm{~mL}$ of a $100 \mu \mathrm{g} \mathrm{mL} \mathrm{m}^{-1}$ PMCS solution was irradiated by a CW GCSLS-05-007 semiconductor laser device at $808 \mathrm{~nm}$ with a power density of $1 \mathrm{~W} \mathrm{~cm} \mathrm{~cm}^{-2}$ for $10 \mathrm{~min}$. The temperature was monitored by infrared thermal mapping apparatus (FLIR). For in vivo IR thermal imaging, the CD-1 nude mice bearing the HepC2 tumors were i.t. injected with $150 \mu \mathrm{L}$ of a $2 \mathrm{mg} \mathrm{mL}^{-1}$ PMCS-PBS solution. The FLIR monitored the temperature change of the local tumor during irradiation period $\left(808 \mathrm{~nm}, 0.6 \mathrm{~W} \mathrm{~cm}^{-2}, 3 \mathrm{~min}\right.$ ).

For in vitro PA imaging, PA signals of PMCS $\left(100 \mu \mathrm{g} \mathrm{mL}^{-1}\right)$ at different excitations wavelengths were collected by multispectral optoacoustic tomography (MSOT inVision 128, iThera medical, Germany). For in vivo PA imaging, $150 \mu \mathrm{L}$ of PMCS-PBS solution $\left(2 \mathrm{mg} \mathrm{mL}^{-1}\right)$ was i.t. injected into tumor-bearing CD-1 nude mice. PA signals were recorded by MSOT after $10 \mathrm{~min}$.

In Vivo Combination Therapy: The male nude mice bearing HepC2 tumors $(n=12)$ were randomly distributed into four groups: i) a control group (PBS injection); ii) NIR group (laser only irradiation, $0.6 \mathrm{~W} \mathrm{~cm}-2,3 \mathrm{~min}$ ); iii) PMCS group (PMCS i.t. injection, $20 \mathrm{mg} \mathrm{kg}^{-1}$ ); and iv) PMCS+NIR group (PMCS i.t. injection, $20 \mathrm{mg} \mathrm{kg}^{-1}, 0.6 \mathrm{~W} \mathrm{~cm}$, $3 \mathrm{~min}$ ). The CW GCSLS-05-007 semiconductor laser device at $808 \mathrm{~nm}$ was used as a source of laser light. During the treatment period, the tumor size was measured with calipers and the body weights were also recorded every day. The tumor volume was calculated by the formula: tumor volume $=($ tumor length $) \times(\text { tumor width })^{2} / 2$. After $30 \mathrm{~d}$, all mice were sacrificed, and tumor tissues and major organs (heart, liver, spleen, lung, and kidney) harvested and fixed in $10 \%$ formalin, embedded in paraffin, sectioned at $5 \mu \mathrm{m}$, and stained with H\&E. After H\&E staining, the slides were examined with optical microscopy (Nikon Eclipse Ti-S, CCD: Ri1).

In Vivo Systemic Toxicity: Healthy ICR female mice $(n=3)$ were used in this experiment. The first mouse received a dose one step below the assumed estimate of the maximum tolerated dose (MTD) according to a pre-reported method. Doses of $400,200,150,100,50,25$, and $12.5 \mathrm{mg} \mathrm{kg}^{-1}$ were i.v. administered. The clinical manifestations were observed carefully, and body weights recorded during experiment period. After $16 \mathrm{~d}$, the mice were sacrificed. The major organs were harvested and fixed in $10 \%$ formalin for H\&E staining and microscopic visualization. Blood biochemistry was also examined using venous blood samples from the experimental mice.

\section{Supporting Information}

Supporting Information is available from the Wiley Online Library or from the author.

\section{Acknowledgements}

S.H.W. and L.S. contributed equally to this work. The authors thank Dr. L. Zheng at the Institute of High Energy Physics, Chinese Academy of Sciences for assistance with the XAFS measurement and analysis. The 
work was supported by the National Nature Science Foundation (Nos. 51572271, 31271075, 31270022, 81471784, 51322213, and 21401207), the National Basic Research Program of China (973 Program) under Grant Nos. 2016YFA0201500, 2015CB931900, and 2011CB707700, the Fundamental Research Funds for the Central Universities (buctrc201610, JD1609), and the Strategic Priority Research Program of the Chinese Academy of Sciences (XDB17030200). All animals were maintained and used in accordance with the Guidelines of the Animal Ethics Committee at the Research Center for Eco-Environmental Sciences, Chinese Academy of Sciences.

Received: April 25, 2016

Revised: June 25, 2016

Published online: July 27, 2016

[1] a) X. Huang, I. H. El-Sayed, W. Qian, M. A. El-Sayed, J. Am. Chem. Soc. 2006, 128, 2115; b) L. Cheng, C. Wang, L. Feng, K. Yang, Z. Liu, Chem. Rev. 2014, 114, 10869.

[2] S. S. Lucky, K. C. Soo, Y. Zhang, Chem. Rev. 2015, 115, 1990.

[3] a) A. E. O'Connor, W. M. Gallagher, A. T. Byrne, Photochem. Photobiol. 2009, 85, 1053; b) M. Ethirajan, Y. Chen, P. Joshi, R. K. Pandey, Chem. Soc. Rev. 2011, 40, 340.

[4] a) M. Guo, H. Mao, Y. Li, A. Zhu, H. He, H. Yang, Y. Wang, X. Tian, C. Ge, Q. Peng, X. Wang, X. Yang, X. Chen, G. Liu, H. Chen, Biomaterials 2014, 35, 4656; b) H. Gong, Z. Dong, Y. Liu, S. Yin, L. Cheng, W. Xi, J. Xiang, K. Liu, Y. Li, Z. Liu, Adv. Funct. Mater. 2014, 24, 6492; c) S. Wang, F. Yuan, K. Chen, G. Chen, K. Tu, H. Wang, L. Q. Wang, Biomacromolecules 2015, 16, 2693.

[5] L. A. Muehlmann, G. A. Joanitti, J. R. Silva, J. P. F. Longo, R. B. Azevedo, Braz. J. Med. Biol. Res. 2011, 44, 729.

[6] H.-J. Yoon, W.-D. Jang, J. Porphyrins Phthalocyanines 2013, 17, 16

[7] a) W. Fan, B. Shen, W. Bu, F. Chen, Q. He, K. Zhao, S. Zhang, L. Zhou, W. Peng, Q. Xiao, Biomaterials 2014, 35, 8992; b) K. Hayashi, M. Nakamura, H. Miki, S. Ozaki, M. Abe, T. Matsumoto, T. Kori, K. Ishimura, Adv. Funct. Mater. 2014, 24 503; c) L. Li, T. Liu, C. Fu, H. Liu, L. Tan, X. Meng, J. Biomed. Nanotechnol. 2015, 10, 1784; d) S. Yang, D. Chen, N. Li, Q. Xu, H. Li, F. Gu, J. Xie, J. Lu, Small 2016, 12, 360.

[8] a) A. Punjabi, X. Wu, A. Tokatli-Apollon, M. El-Rifai, H. Lee, Y. Zhang, C. Wang, Z. Liu, E. M. Chan, C. Duan, ACS Nano 2014, 8, 10621; b) W. Fan, B. Shen, W. Bu, X. Zheng, Q. He, Z. Cui, D. Ni, K. Zhao, S. Zhang, J. Shi, Biomaterials 2015, 69, 89; c) Q. Q. Dou, C. P. Teng, E. Ye, X. J. Loh, Int. J. Nanomed. 2015, 10, 419.

[9] R. Jasinski, Nature 1964, 201, 1212.

[10] a) W. Xia, A. Mahmood, Z. Liang, R. Zou, S. Guo, Angew. Chem., Int. Ed. 2015, 55, 2650; b) H. Wang, T. Maiyalagan, X. Wang, ACS Catal. 2012, 2, 781; c) D. Guo, R. Shibuya, C. Akiba, S. Saji, T. Kondo, J. Nakamura, Science 2016, 351, 361.

[11] G. Wu, K. L. More, C. M. Johnston, P. Zelenay, Science 2011, 332, 443.

[12] a) Y. Zhu, B. Zhang, X. Liu, D.-W. Wang, D. S. Su, Angew. Chem., Int. Ed. 2014, 53, 10673; b) D. H. Lee, W. J. Lee, W. J. Lee, S. O. Kim, Y.-H. Kim, Phys. Rev. Lett. 2011, 106, 175502; c) U. I. Kramm, I. Herrmann-Geppert, J. Behrends, K. Lips, S. Fiechter, P. Bogdanoff, J. Am. Chem. Soc. 2016, 138, 635.

[13] L. Shang, H. Yu, X. Huang, T. Bian, R. Shi, Y. Zhao, G. I. Waterhouse, L. Z. Wu, C. H. Tung, T. Zhang, Adv. Mater. 2015, 28, 1668.
[14] a) P. Hu, J. Zhuang, L.-Y. Chou, H. K. Lee, X. Y. Ling, Y.-C. Chuang, C.-K. Tsung, J. Am. Chem. Soc. 2014, 136, 10561; b) L. Shang, T. Bian, B. Zhang, D. Zhang, L. Z. Wu, C. H. Tung, Y. Yin, T. Zhang, Angew. Chem., Int. Ed. 2014, 53, 250.

[15] P. P. Adiseshaiah, J. B. Hall, S. E. McNeil, WIREs Nanomed. Nanobiotechnol. 2010, 2, 99.

[16] L. Li, C. Chen, H. Liu, C. Fu, L. Tan, S. Wang, S. Fu, X. Liu, X. Meng, H. Liu, Adv. Funct. Mater. 2016, 26, 4252.

[17] C. M. Hessel, V. P. Pattani, M. Rasch, M. G. Panthani, B. Koo, J. W. Tunnell, B. A. Korgel, Nano Lett. 2011, 11, 2560.

[18] S. Wang, A. Riedinger, H. Li, C. Fu, H. Liu, L. Li, T. Liu, L. Tan, M. J. Barthel, G. Pugliese, ACS Nano 2015, 9, 1788.

[19] a) Y. Chen, K. Ai, J. Liu, G. Sun, Q. Yin, L. Lu, Biomaterials 2015, 60 111 ; b) X. Liang, Y. Li, X. Li, L. Jing, Z. Deng, X. Yue, C. Li, Z. Dai, Adv. Funct. Mater. 2015, 25, 1451; c) J. Yu, C. Yang, J. Li, Y. Ding, L. Zhang, M. Z. Yousaf, J. Lin, R. Pang, L. Wei, L. Xu, F. Sheng, C. Li, G. Li, L. Zhao, Y. Hou, Adv. Mater. 2014, 26, 4114.

[20] L. Zhang, Z. Su, F. Jiang, L. Yang, J. Qian, Y. Zhou, W. Li, M. Hong, Nanoscale 2014, 6, 6590.

[21] V. Kumar, V. Kumar, G. Reddy, R. Pasricha, RSC Adv. 2015, 5, 74342.

[22] D. Geng, S. Yang, Y. Zhang, J. Yang, J. Liu, R. Li, T.-K. Sham, X. Sun, S. Ye, S. Knights, Appl. Surf. Sci. 2011, 257, 9193.

[23] C. He, J. J. Zhang, P. K. Shen, J. Mater. Chem. A 2014, 2, 3231.

[24] A. Zitolo, V. Goellner, V. Armel, M. T. Sougrati, T. Mineva, L. Stievano, E. Fonda, F. Jaouen, Nat. Mater. 2015, 14, 937.

[25] a) J. Ge, M. Lan, B. Zhou, W. Liu, L. Guo, H. Wang, Q. Jia, G. Niu, X. Huang, H. Zhou, X. Meng, P. Wang, C. S. Lee, W. Zhang, X. Han, Nat. Commun. 2014, 5, 4596; b) A. I. Gomes, L. O. Lunardi, J. M. Marchetti, C. N. Lunardi, A. C. Tedesco, Photomed. Laser Surg. 2006, 24, 514; c) L. Gao, R. Liu, F. Gao, Y. Wang, X. Jiang, X. Gao, ACS Nano 2014, 8, 7260.

[26] a) Y. Liu, K. Ai, J. Liu, M. Deng, Y. He, L. Lu, Adv. Mater. 2013, 25, 1353; b) J. Liu, C. Wang, X. Wang, X. Wang, L. Cheng, Y. Li, Z. Liu, Adv. Funct. Mater. 2015, 25, 384; c) H. Liu, D. Chen, L. Li, T. Liu, L. Tan, X. Wu, F. Tang, Angew. Chem. 2011, 123, 921; d) L. Cheng, J. Liu, X. Gu, H. Gong, X. Shi, T. Liu, C. Wang, X. Wang, G. Liu, H. Xing, W. Bu, B. Sun, Z. Liu, Adv. Mater. 2014, 26, 1886; e) H. Liu, T. Liu, X. Wu, L. Li, L. Tan, D. Chen, F. Tang, Adv. Mater. 2012, 24, 755.

[27] J. Liu, X. Zheng, L. Yan, L. Zhou, G. Tian, W. Yin, L. Wang, Y. Liu, Z. Hu, Z. Gu, ACS Nano 2015, 9, 696.

[28] a) X. Tu, L. Wang, Y. Cao, Y. Ma, H. Shen, M. Zhang, Z. Zhang, Carbon 2016, 97, 35; b) L. Wang, Q. Sun, X. Wang, T. Wen, J.-J. Yin, P. Wang, R. Bai, X.-Q. Zhang, L.-H. Zhang, A.-H. Lu, C. Chen, J. Am. Chem. Soc. 2015, 137, 1947; c) L. Zhou, K. Dong, Z. Chen, J. Ren, X. Qu, Carbon 2015, 82, 479 .

[29] a) P. Vijayaraghavan, C. H. Liu, R. Vankayala, C. S. Chiang, K. C. Hwang, Adv. Mater. 2014, 26, 6689; b) P. Kalluru, R. Vankayala, C. S. Chiang, K. C. Hwang, Angew. Chem., Int. Ed. 2013, 52, 12332.

[30] a) I. Jutooru, A. S. Guthrie, G. Chadalapaka, S. Pathi, K. Kim, R. Burghardt, U.-H. Jin, S. Safe, Mol. Cell. Biol. 2014, 34, 2382; b) L. Yang, L. Zhu, W. Dong, Y. Cao, L. Lin, Z. Rong, Z. Zhang, G. Wu, Int. Orthop. 2014, 38, 205.

[31] D. Chen, C. Wang, X. Nie, S. Li, R. Li, M. Guan, Z. Liu, C. Chen C. Wang, C. Shu, L. Wan, Adv. Funct. Mater. 2014, 24, 6621.

[32] C. L. Bayer, S. Y. Nam, Y.-S. Chen, S. Y. Emelianov, J. Biomed. Opt 2013, 18, 016001 